\title{
Protection of the Liuzheng Water Source: A Karst Water System in Dawu, Zibo, China
}

\author{
Henghua Zhu ${ }^{1,2}$, Yanan Dong ${ }^{3}$, Liting Xing ${ }^{3, *}$, Xiaoxun Lan ${ }^{3}$, Lizhi Yang ${ }^{2}$, Zhizheng Liu ${ }^{2}$ and \\ Nongfang Bian ${ }^{4}$ \\ 1 School of Environmental Studies, China University of Geosciences, Wuhan 430074, China; \\ zhuhenghua12@163.com \\ 2 Shandong Institute of Geological Survey, Jinan 250000, China; yanglizhi23@163.com (L.Y.); \\ liuzhizheng12@163.com (Z.L.) \\ 3 School of Water Conservancy and Environment, University of Jinan, Jinan 250022, China; \\ dongyanan96@163.com (Y.D.); jndxlanxx@163.com (X.L.) \\ 4 Administrative Department of Dawu Water Source Area of Zibo, Zibo 255400, China; biannongfang@163.com \\ * Correspondence: stu_xinglt@ujn.edu.cn; Tel.: +86-531-8276-9233
}

Received: 5 March 2019; Accepted: 2 April 2019; Published: 4 April 2019

\begin{abstract}
The Dawu water source is a rare, large-scale groundwater source located in northern China. The water supply function from this water source has, however, been lost due to anthropogenic pollution. In order to fully utilize valuable groundwater resources, a new water source of urban domestic water in Liu Zheng is planned. In this study, a tracer test and a numerical simulation method are used to examine the hydraulic connection between the Liuzheng water source and the Wangzhai industrial park; to optimize the exploitation layout of the Liuzheng water source and Dawu water source; and to propose the extent of the Liuzheng water source protection area. Results indicate that: (1) Karst development in the study area is uneven, and the Wangzhai area is a recharge area of the Liuzheng water source; (2) it is predicted that the groundwater flow field will not be significantly changed when a groundwater volume of $150,000 \mathrm{~m}^{3} /$ day is exploited from the Liuzheng water source; (3) it is predicted that the proposed chemical park in Wangzhai will gradually pollute to the groundwater in the northern area of Liuzheng; and (4) results using the empirical formula method and the numerical simulation method indicate that the area of the primary protection area of the Liuzheng water source is about $0.59 \mathrm{~km}^{2}$, and the area of the secondary protection area is about $14.98 \mathrm{~km}^{2}$. Results from this study provide a certain technical basis for the exploitation and protection of groundwater in the Liuzheng water source.
\end{abstract}

Keywords: tracer test; numerical simulation; pollution; division of protection areas; Liuzheng water source

\section{Introduction}

The karst landforms are widely distributed around the world, and karst water provides drinking water to nearly a quarter of the world's population. In China, the total area of bare limestone is about 1.3 million square kilometers, accounting for $13.5 \%$ of the total area of the country, and covered limestone buried underground is more extensive. During the long geological history evolution, landforms such as gully, dissolved depression, dry valley, blind valley, falling water cave, and skylight are formed. The soluble rocks can be dissolved and eroded by groundwater along the layers, joints or structural fractures, and formed underground passages, rapidly moving through karst fissures, karst conduits, etc. Groundwater in the karst area is extremely easy to be polluted, which means that karst aquifer has a high degree of vulnerability [1-3]. The multiple conduit flow of karst medium leads to rapid contamination, while the diffuse flow forms persistent contamination [4]. Due to the 
uneven development of karst as well as the complex and variable movement of groundwater flow, people try to study the migration of pollutants in karst water from different scales using different methods, such as isotopes [5], tracer test [6], pumping test [7], numerical simulation [8-10], indoor experiment [11], and so on. For example, Hamdan et al. [12] revealed the characteristics of groundwater vulnerability to pollution with the method of combining the stable isotopic (oxygen and hydrogen) and data of water temperature, spring discharge, and turbidity. Morales et al. [13] depicted the transport characteristics along preferential flow paths in karst aquifers by analyzing data obtained in 26 tracer tests in Basque.Maloszewski et al. [14] combined the application of lumped-parameter models to establish a measurement model for ${ }^{18} \mathrm{O}$ and tritium in precipitation and springs, and obtained mean values of hydraulic parameters. Therefore, in order to effectively manage vulnerable karst water systems, specific exploration techniques and modeling methods are required to master, studying the media characteristics and hydrodynamic field characteristics of the karst area [15,16].

Previous studies have indicated that the majority of water in karst areas with intense anthropogenic activity has been contaminated to different degrees [17-19]. Pollution sources are derived mainly from industrial, agricultural and domestic pollution [20], with industrial and agricultural pollution being the main source points. For example, industrial production activities produce refractory organic pollutants, heavy metals, etc., which cause different degrees of pollution to groundwater systems [21]. Currently, water pollution in karst areas has certain universality in the north and south of China, as well as in other karst areas around the world. Water pollution associated to the chemical industry in karst areas is a notably serious issue [22-24].

In order to protect groundwater resources and prevent groundwater pollution risks, methods suitable for the division of groundwater source protection areas have been examined [25-27]. For example, Andreo et al. [28] used karst water replenishment conditions combined with groundwater flow rate to delineate the risk zone for karst water pollution. With the rapid development of computer science, numerical methods have been widely used. Numerical methods can not only simulate large-scale karst water movementand evaluate karst water resources [1], but also predict groundwater pollution processes [29]. For instance, Rudakov et al. [8] used two-dimensional and three-dimensional flow to simulate the migration of pollutants in groundwater. The migration of characteristic pollutants in aquifers was investigated by Saghravani using FEFLOW [9], and Rao Lei et al. [10] used the Visual Modflow to simulate and study the migration of pollutants in groundwater after the leakage of sewage from an industrial park in Jiangjin District, Chongqing. In order to delineate groundwater protection zones, a large number of studies have been undertaken [30-33], with the majority using empirical methods to determine the extent of protected areas [34]. In order to predict the spread of pollutants over long-term scales [35], the numerical method has advantages over traditional empirical formula methods, however the numerical method requires more hydrogeological exploration work.

The Dawu water source is a rare large-scale karst water source. However, an oil spill by the Qilu Petrochemical Company in the mid-1980s resulted in groundwater pollution in this water source [36]. In order to control karst water pollution in this area, hydraulic interception measures were implemented in the upper reaches of the Dawu water source in 1992. However, these measures have not protected the Dawu water source as petroleum pollutants in some areas still exceed standard guideline values. At present, the Dawu water source has lost its water supply function. In order to alleviate water supply issues in this area, new water sources are urgently needed. According to previous analysis, the Dawu water source area and the upstream Liuzheng area belong to the same hydrogeological unit; the Liuzheng section in the runoff area has a large output capacity from a single well and it has good water quality [37]. It is therefore proposed that a new water source is created in the Liuzhen area. As a new petrochemical park is proposed in the Wangzhai area, it is important to study the impact this park may have on the groundwater environment of the Liuzheng water source.

Therefore, this paper uses the tracer test to reveal the characteristics of medium field, uses numerical simulation to grasp the characteristics of groundwater flow field, and combines the tracer test, empirical formula and numerical simulation to divide the protection area of karst water source area. 


\section{Study Area}

The study area belongs toa warm temperate continental monsoon climate. The annual average temperature is $12.3-13.1^{\circ} \mathrm{C}$, and the average annual precipitation is $640.50 \mathrm{~mm}$. The rivers in the area are all rain-source type, and the terrain is high in the south and low in the north. The terrain in the south is a low mountain and hilly, and the highest elevation is $380 \mathrm{~m}$. The northern part is connected to the sloped plain in front ofa mountain, and the lowest elevation is $40 \mathrm{~m}$. Cambrian carbonate rocks are exposed in the southern high mountains, central Ordovician limestones are exposed in the low hills and Ordovician limestones are concealed to the north in the Carboniferous-Permian sand sheets. Below the rock strata, Quaternary loose rock stratais widely distributed in the piedmont plain in the north, and the Carboniferous-Permian coal-bearing strata constitutes the water-blocking barrier of fractured karst water in the north. The fault structure is developed in the area. The central Zihe fault zone is the largest concealed fault zone in this area, which constitutes the water-conducting zone from the south to the north. The Liuzheng water source is located in the middle of this fault zone (Figure 1). The carbonate fractured karst aquifers in the southern region and the Quaternary loose-rock-porous aquifers in the northern region are the main aquifers in the study area. The Quaternary loose-rock-porous aquifer is mainly distributed in the floodplain of the Zihe River and along its two sides, the plain area in the north and the alluvial fan of the Zihe River. The carbonate fractured karst aquifer is mainly distributed in bare mountainous areas to piedmont concealed zones.

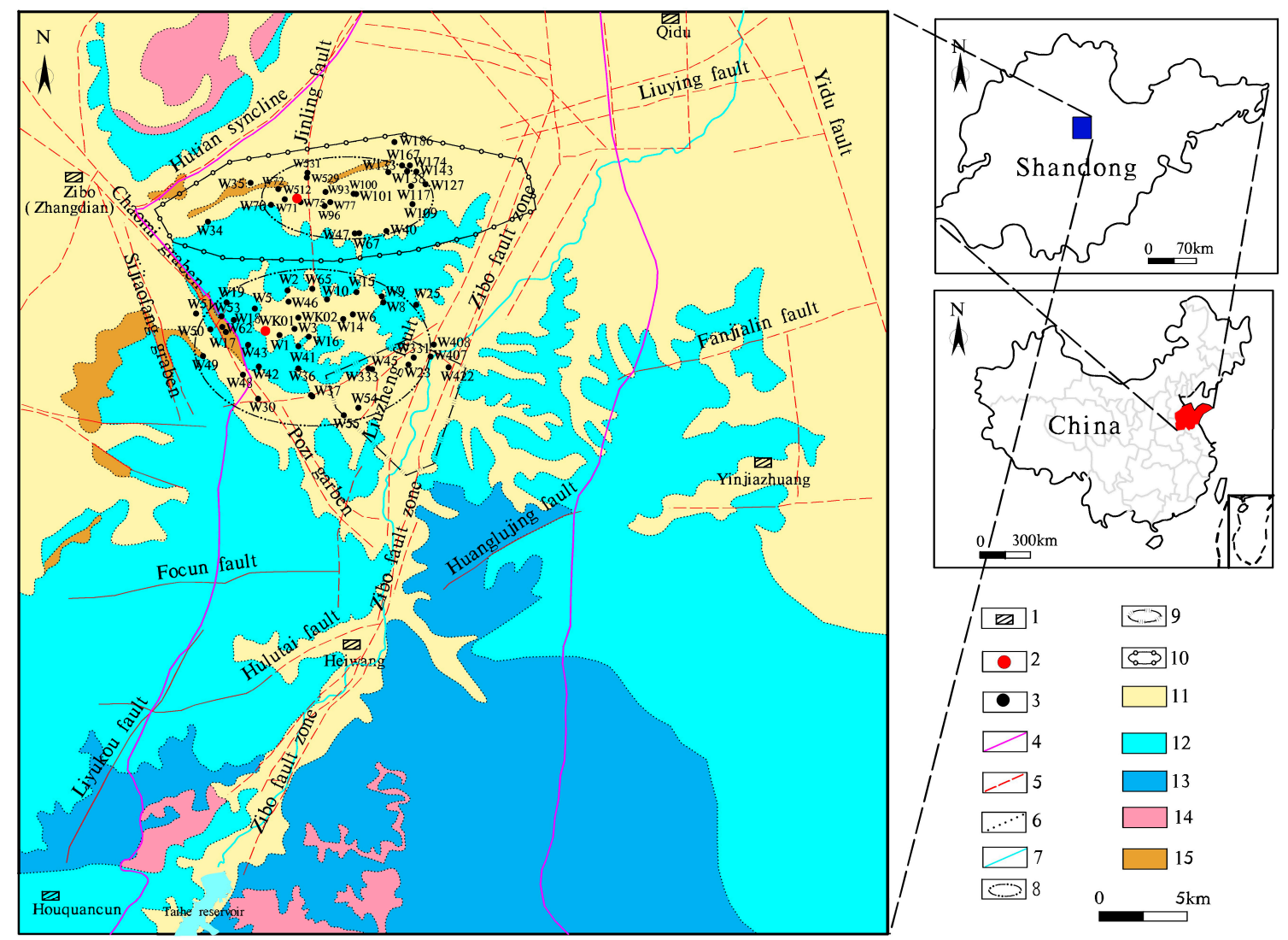

Figure 1. Geology of the study area. 1: Village; 2: Source well; 3: Observation well; 4: Simulation zone boundary; 5: Fault; 6: Geological boundary; 7: River; 8: Tracer test area; 9: Dawu water source exploitation area; 10: Liuzheng water source exploitation area; 11: Quaternary loose layer; 12: Ordovician limestone; 13: Cambrian limestone; 14: Magmatic rock; 15: Carboniferous-Permian sand shale.

Water recharge in the study area is mainly by atmospheric precipitation and water extraction is mainly due to artificial exploitation. Total water resources in the region are about $410,000 \mathrm{~m}^{3} /$ day, 
of which artificial groundwater exploitation is mainly concentrated in the northern region, with exploitation volume accounting for about $350,000 \mathrm{~m}^{3} /$ day [38]. However, groundwater pollution in this area caused by the oil spill in the 1980s has rendered it not suitable for domestic use. It is therefore necessary to optimize the exploitation layout of the Dawu and Liuzheng areas, and to divide the Liuzheng water source protection area with the aim to maximize the benefits of groundwater resources.

\section{Methods}

\subsection{Tracer Test Arrangement}

In order to examine the hydraulic connection between the Wangzhai, Hougao and Liuzheng areas, WK01 and W512 were used as source wells for field tracer tests (Figure 1). On 7March 2017, $210 \mathrm{~kg}$ of ammonium molybdate was injected into the WK01 well in the Wangzhai experimental area, and 27 monitoring wells were established. A total of 379 water samples were collected from the following day until 20June 2017. On 16November2017, $200 \mathrm{~kg}$ of ammonium molybdate was injected into the W512 well in the Hougao experimental area, and 25 monitoring wells were established. A total of 350 water samples were collected from the following day until 9March 2018. For both experiment sites, the aquifers of the source and sampling holes are Ordovician limestone aquifers.

Prior to the open tracer test, molybdenum ion background values from the Wangzhai and Hougao experimental areas were recorded.After the tracer was injected, in the encrypted observation area within $2 \mathrm{~km}$ from the source point, the monitoring frequency was once a day; the area outside the encryption area was sampled once every three days. Monitoring holes close to the source well were sampled first.As the tracer migrated, the sampling frequency of the surrounding area was gradually encrypted.The atomic absorption spectrophotometer-graphite furnace method was used to measure molybdenum ion concentrations, and the detection limit is $0.5 \mathrm{ppb}$. The water level measurement at the monitoring points was synchronized during the tracer test.

\subsection{Groundwater Flow Model}

According to the hydrogeological conditions of the study area, the aquifer in the study area was generalized into a heterogeneous, anisotropic, three-dimensional unsteady groundwater flow model. The mathematical model of groundwater flow can be written as [39]:

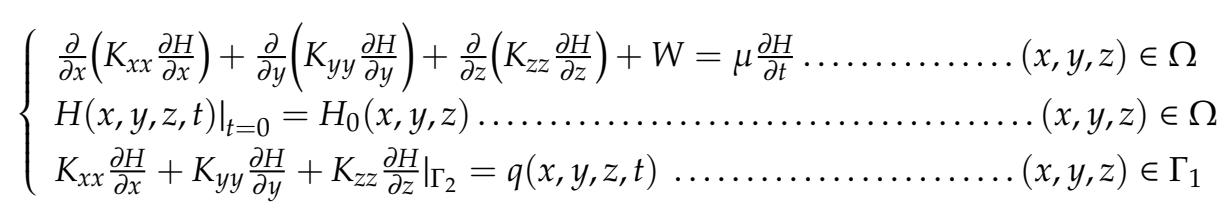

where $K_{x x}, K_{y y}$ and $K_{z z}$ are values for hydraulic conductivity (m/day) along the $x, y$, and $z$ axes, respectively; $\mu$ is the specific storage or specific yield; $H(\mathrm{~m})$ is the potentiometric head; $H_{0}(\mathrm{~m})$ is the potentiometric head at the initial moment; $W$ is a volumetric flux per unit volume representing sources and/or sinks of water; $\Omega$ is the simulation area; and $\Gamma_{1}$ is the boundary.

According to the drilling data and hydrogeological conditions, the model was divided into three layers in the vertical direction: (i) The Quaternary pore aquifer; (ii) the relatively weak aquifer; and (iii) the fractured karst aquifer. The planar area was divided by a discrete method of rectangular finite difference and the cell size was $500 \mathrm{~m} \times 500 \mathrm{~m}$. The east-west boundary of the calculation zone was the water-blocking boundary; the north was the lateral runoff discharge; and in the south, the west side of the Taihe Reservoir was the lateral runoff recharge. The main recharge items in the study area were the recharge of precipitation infiltration, and other recharges include the lateral runoff recharge, river leakage recharge, and recharge of reservoirs during the flood season. The main extraction process is artificial exploitation. The initial flow field used the groundwater flow field on 1September 2018. 


\subsection{Solute Transport Model}

In order to predict the pollution impact of the proposed chemical park on the groundwater of the Liuzheng water source, the mathematical model of solute transport is as follows [39]:

$$
\left\{\begin{array}{l}
\frac{\partial C}{\partial t}=\frac{\partial}{\partial x_{i}}\left(D_{i j} \frac{\partial C}{\partial x_{i}}\right)-\frac{\partial}{\partial x_{i}}\left(V_{i} C\right)+\frac{q_{s}}{n} C_{s}+\sum R_{k} \ldots \ldots \ldots \ldots \ldots(x, y, z) \in \Omega \\
\left.C(x, y, z, t)\right|_{t=0}=C_{0}(x, y, z) \ldots \ldots \ldots \ldots \ldots \ldots \ldots \ldots \ldots \ldots \ldots \ldots \ldots \ldots \ldots \ldots \ldots \ldots \ldots \ldots \\
\end{array}\right.
$$

where $C(\mathrm{mg} / \mathrm{L})$ is the concentration of pollutants; $D_{i j}\left(\mathrm{~m}^{2} /\right.$ day) is the hydrodynamic dispersion coefficient; $V_{i}(\mathrm{~m} /$ day) is the groundwater permeation flow rate; $t$ (day) is time; $n$ is the porosity; $C_{s}(\mathrm{mg} / \mathrm{L})$ is the concentration of source sink item; $q_{s}\left(\mathrm{~m}^{3} /\right.$ day) is the unit flow; $\Sigma R_{k}$ is the chemical reaction term; $C_{0}(\mathrm{mg} / \mathrm{L})$ is the initial concentration of pollutants; and $\Omega$ is the simulation area.

Based on the water flow model, the solute transport model was established. Combined with the composition of pollutants discharged from various chemical enterprises in the plant area [40], the conventional component $\mathrm{Cl}^{-}$was selected as the simulation predictor. Assuming the initial concentration of the region was 0 , the pollution source was assumed to be a point source. Leakage was set to $5000 \mathrm{~m}^{3} /$ day, and the concentration of the pollutant $\mathrm{Cl}^{-}$was set to $3000 \mathrm{mg} / \mathrm{L}$.

\section{Results and Analysis}

\subsection{Anisotropy of Karst Development}

\subsubsection{Anisotropy of Runoff Channels}

Tracer detection values were set at concentrations 5-times greater than background values at the observation wells. Molybdenum tracer was detected in eight observation wells in the Wangzhai test area and in ten observation wells in the Hougao experimental area. The tracer concentration curves form the observation wells in Wangzhai and Hougao were divided into single peak, double peak and triple peak types (Table 1), and the three major categories were subdivided into different specific forms. The single-peak curve was divided into slightly symmetrical and asymmetric types; the double-peak curve was divided into high-low and low-high types; and the three-peak curve was divided into high-low-low and low-high-low types.

Single peak concentration curves accounted for the majority of tracer curves $(62.5 \%)$ from wells in the Wangzhai test area, followed by triple peak curve $(25 \%)$ and double peak curve $(12.5 \%)$. Results from observation wells in the Hougao test area recorded double peak $(50 \%)$ and single peak $(40 \%)$ as the dominant tracer concentration curves; the triple peak curve type accounted for $10 \%$. The various types of curves reflect the difference in the degree of aquifer fissure development, with a single channel and two or three main channels [41]. The concentration curve obtained by the tracer test indicates that karst development in the Wangzhai and Hougao areas of Zibo are characterized by the coexistence of karst pores, karst fissures, fractures and pipelines. The range of tracer diffusion suggest that the main direction of the Hougao experimental area is northward and eastward, and the mainstream of the Wangzhai experimental area is to the southeast (Figure 2). Therefore, the Wangzhai section is a supply area of the Dawu and Liuzheng water sources. 
Table 1. Tracer concentration curve type of observation well.

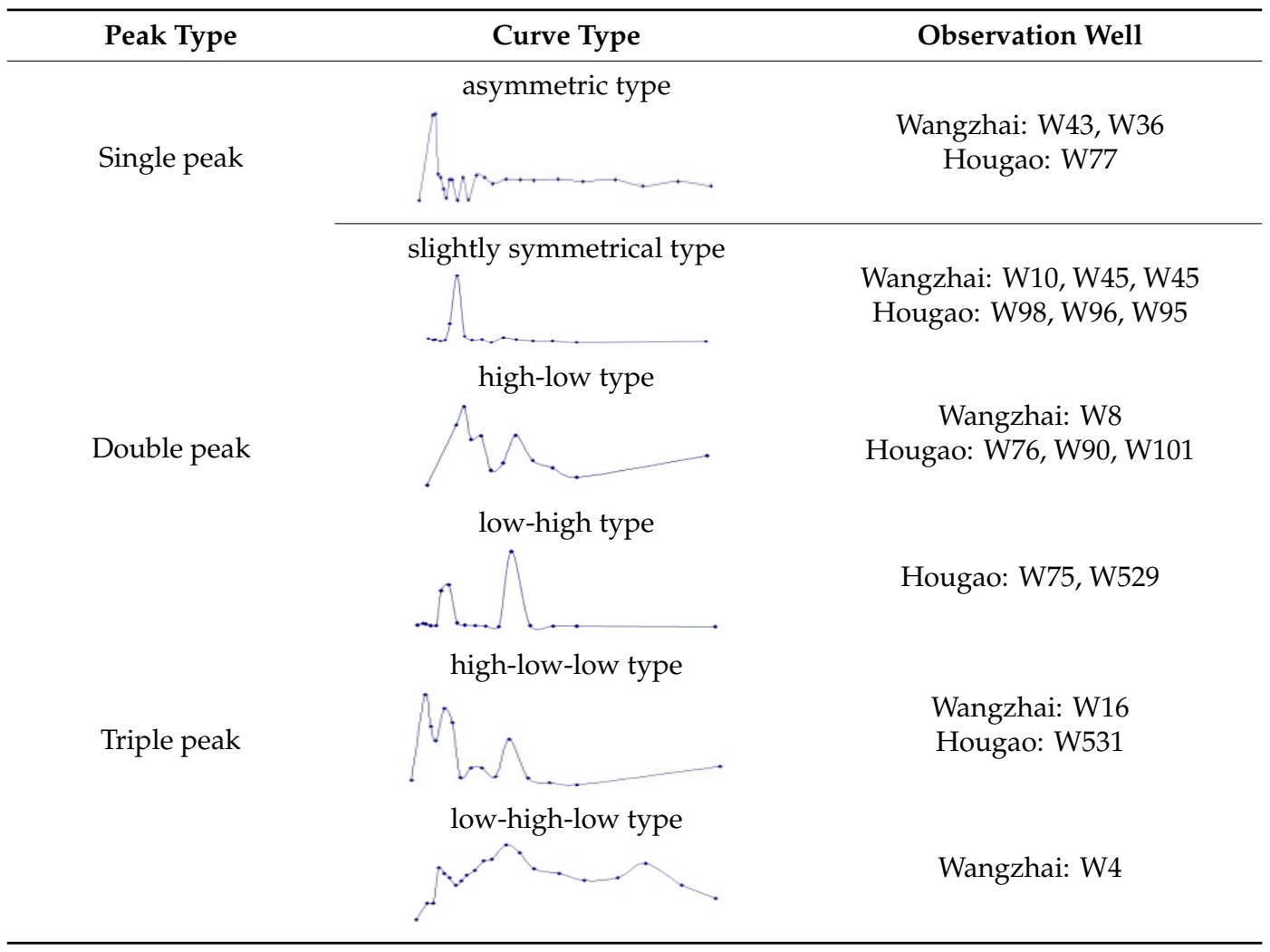

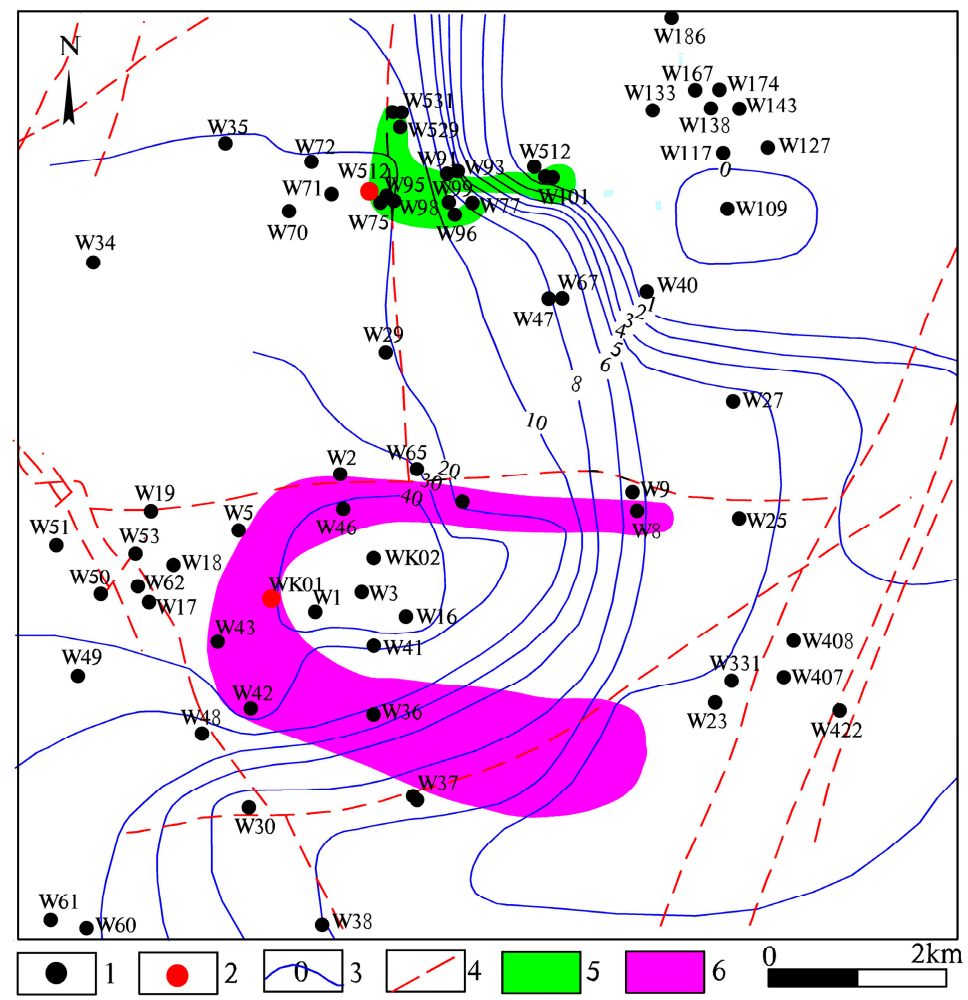

Figure 2. The range of tracer diffusion. 1: Observation well; 2: Source well; 3: Water level line/m; 4: Fault; 5: Tracer diffusion zone in Wangzhai; 6: Tracer diffusion zone in Hougao. 


\subsubsection{Anisotropy of Dispersion Coefficient}

Assuming that the instantaneous injection of tracer in the steady flow field forms a two-dimensional dispersion, tracer migration will mainly be affected by mechanical dispersion, ignoring the influence of molecular diffusion [42]. The concentration distribution expression of a point $(x, y)$ on the plane will therefore be:

$$
c=\frac{M}{4 n \pi \sqrt{\alpha_{L} \times \alpha_{T}} t} \exp \left\{-\frac{1}{4 u t}\left[\frac{(x-u t)^{2}}{\alpha_{L}}+\frac{y^{2}}{\alpha_{T}}\right]-\lambda t\right\}
$$

where $c(\mathrm{mg} / \mathrm{L})$ is the tracer concentration at $(x, y)$ point; $n$ is the porosity; $u(\mathrm{~m} /$ day) is the average pore flow velocity of the groundwater, and $\alpha_{L}(\mathrm{~m})$ and $\alpha_{T}(\mathrm{~m})$ are longitudinal and transverse dispersion, respectively.

According to the test data, it was possible to determine the peak moment of molybdenum ion concentration in the observation well $\left(t_{m}\right)$, to organize the measured data with $\left(t_{m}{ }^{2} / t+t\right)$ as $\mathrm{x}$ and $\left(\ln C t+t_{m} / t\right)$ as $\mathrm{y}$, and to the identify slope (B) and intercept $(\ln \mathrm{A})$ of the fitted line using linear regression. Similarly, the source hole data was collated and a scatter plot with $t$ as $\mathrm{x}$ and $\ln C t$ as y was drawn. The intercept $(\ln a)$ of the fitted straight line was obtained. Then, these values were substituted into Formula 4, which can give the vertical and horizontal dispersion [43].

$$
\left\{\begin{array}{l}
\frac{x^{2}}{\alpha_{L}}-\frac{y^{2}}{\alpha_{T}}=4 u\left(B t_{m}^{2}+t_{m}\right) \\
\ln A-\ln a=\frac{x}{2 \alpha_{L}} \\
B=\frac{u}{4 \alpha_{L}}+\lambda
\end{array}\right.
$$

where $x(\mathrm{~m})$ and $y(\mathrm{~m})$ are the transverse distance and longitudinal distance from the observation hole to the source hole, respectively; $u$ (m/day) is the average pore flow velocity of the groundwater; and $t_{m}$ (day) is the time when the tracer concentration reached the peak time. The Equations are solved to obtain the longitudinal and transverse dispersion, which are substituted into the Equations $D_{L}=\alpha_{L} v$ and $D_{T}=\alpha_{T} v$ to obtain the longitudinal and transverse dispersion coefficients (Table 2).

\begin{tabular}{|c|c|c|c|c|}
\hline Source Well & Direction & $\begin{array}{l}\text { Observation } \\
\text { Well }\end{array}$ & $\begin{array}{l}\text { Longitudinal Dispersion } \\
\text { Coefficient }\left(\mathrm{m}^{2} / \text { day }\right)\end{array}$ & $\begin{array}{c}\text { Transverse Dispersion } \\
\text { Coefficient }\left(\mathrm{m}^{2} / \text { day }\right)\end{array}$ \\
\hline \multirow{4}{*}{$\begin{array}{c}\text { WK01 } \\
\text { (Wangzhai) }\end{array}$} & Southeast & W36 & 3.71 & 0.25 \\
\hline & Southeast & W45 & 6.41 & 0.83 \\
\hline & Southwest & W43 & 2.38 & 0.52 \\
\hline & Northeast & W8 & 5.76 & 0.79 \\
\hline \multirow{4}{*}{$\begin{array}{c}\text { W512 } \\
\text { (Hougao) }\end{array}$} & North & W31 & 12.83 & 0.93 \\
\hline & East & W101 & 3.06 & 0.4 \\
\hline & East & W75 & 2.71 & 0.22 \\
\hline & Southeast & W95 & 4.56 & 0.62 \\
\hline
\end{tabular}

Table 2. Calculation results of the dispersion coefficient.

The dispersion coefficient in all directions of the test area is anisotropic, and it has no obvious correlation with the flow rate and tracer concentration. Therefore, the hydrodynamic field in this area is simulated using a three-dimensional flow model.

\subsection{Water Level Prediction of the Liuzheng Water Source}

According to the exploration data of the Liuzheng water source [38], the identification and inspection stage of the model was completed using data spanning June 2017 to September 2018. The permeability coefficient, elastic drainable porosity, specific yield and rainfall infiltration coefficient of each division of the study were also determined. Since the Liuzheng area is considered as a new water supply source, exploitation layout was appropriately adjusted according to previous regional groundwater exploitation volume. Therefore, the amount of exploitation in the northern 
part of the Dawu area was reduced and the amount of artificial exploitation in the Liuzheng areawas increased. Precipitation data from 2008-2017, including the dry water series, was selected for our study. After debugging the exploitation capacity of the Dawu water and Liuzheng water sources several times, the dynamic change of the groundwater level in the Liuzheng area over the next 10 years was predicted based on an exploitation rate of $150,000 \mathrm{~m}^{3} /$ day.

Results indicate that when the total volume of the karst water system is kept constant, water extraction in the Liuzheng area is about $150,000 \mathrm{~m}^{3} /$ day, and 200,000 $\mathrm{m}^{3} /$ day in the Dawu water source. In this case, although the groundwater level of the Liuzheng is reduced in dry years, groundwater is quickly replenished and the water level is able to increase in wet years (Figure 3). The groundwater system can maintain a dynamic equilibrium for many years. Figure 4 showed the groundwater flow field of the Liuzhengarea during the wet season after adjusting the mining layout. There is no significant change in the regional natural groundwater flow field. The average water level in the mining center droppedfrom about $27 \mathrm{~m}$ adjusting the mining layout to about 22 mafter adjusting the mining layout, that is, the mean water level drop was about $5 \mathrm{~m}$, and no hydrogeological problems will appear, such as karst collapse.

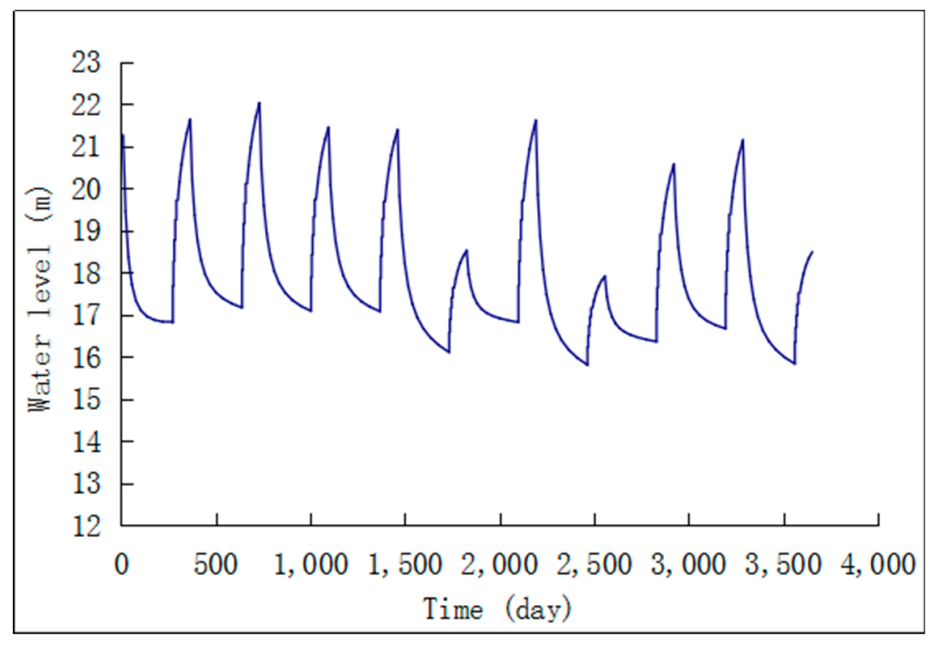

Figure 3. Prediction curve of water level change in the LK11 well.

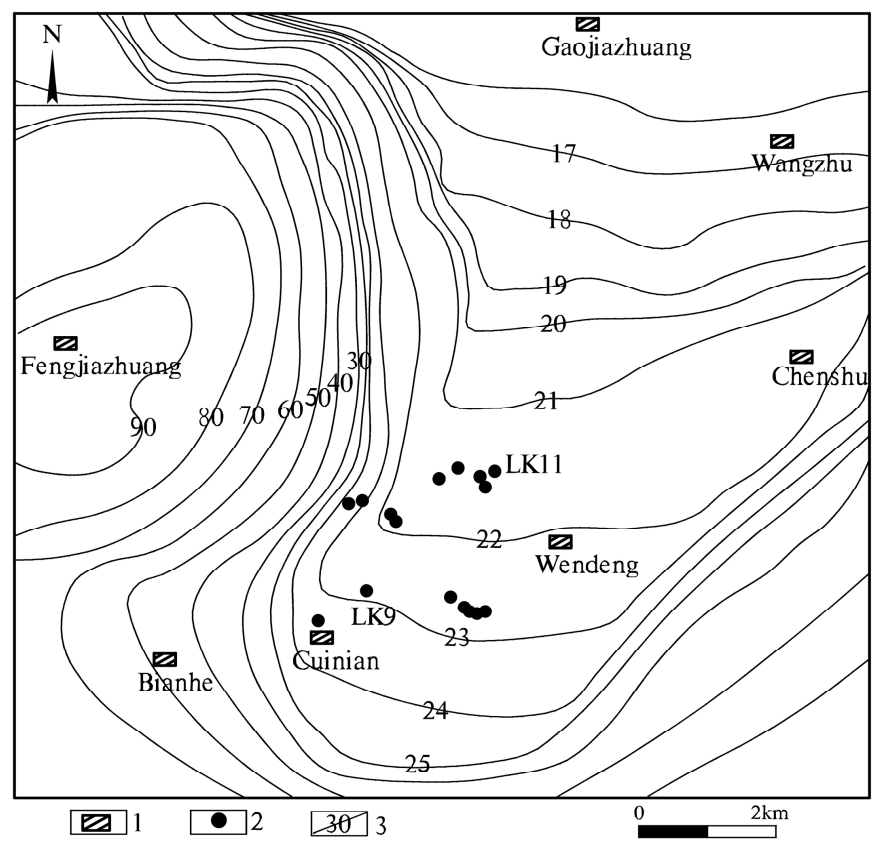

Figure 4. Groundwater plane flow field. 1: village; 2: mining well; 3: groundwater level contour (m). 
After optimizing the exploitation layout, exploitation of high-quality groundwater in the Liuzheng area increased, and the source of inferior groundwater in the north of the Dawu water source was intercepted, thereby greatly improving the utilization efficiency of groundwater. These results indicate that the exploitation of $150,000 \mathrm{~m}^{3}$ /day of water from the Liuzheng water source is feasible for domestic use.

\subsection{Pollution Prediction}

Based on the groundwater flow simulation when the amount of groundwater exploitation in the Liuzheng water source is $150,000 \mathrm{~m}^{3} /$ day, the regional pollutant transport after 10, 30 and 50 years of continuous wastewater discharge (Figure 5), and the concentration curve of $\mathrm{Cl}^{-}$in the mining well location of Liuzheng water source (Figure 6) were modeled.

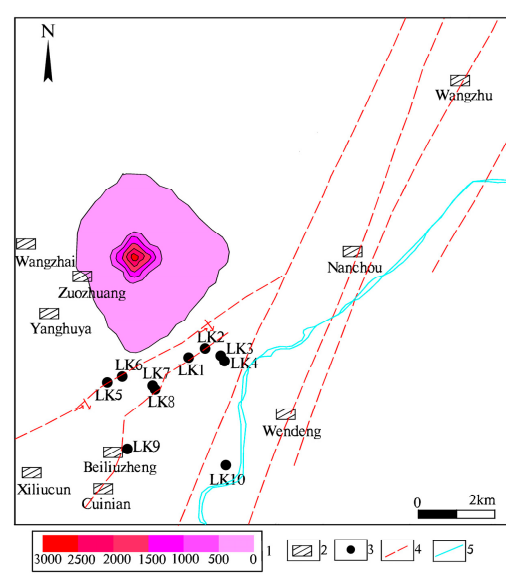

(a)

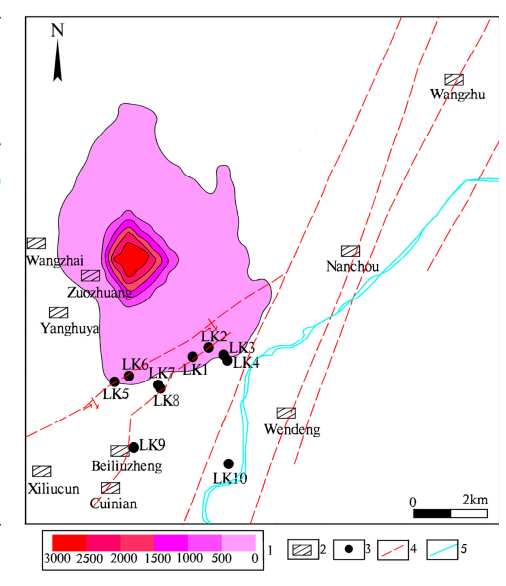

(b)

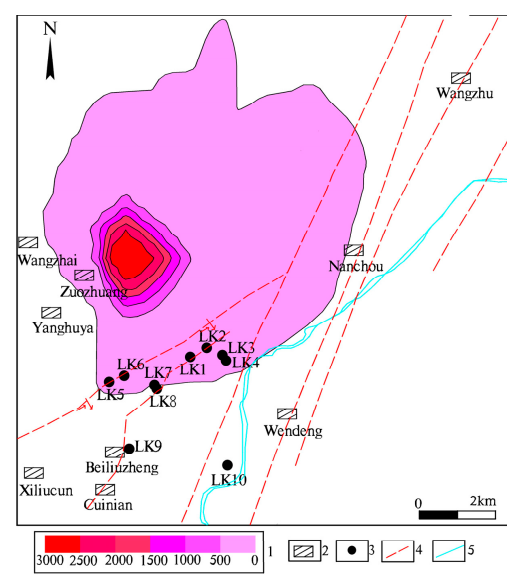

(c)

Figure 5. Plane range of solute migration. (a) 10 years, (b) 30 years, (c) 50 years; 1: Concentration of $\mathrm{Cl}^{-}$(mg/L); 2: Village; 3: Liuzheng water source mining well; 4: Fault; 5: River.

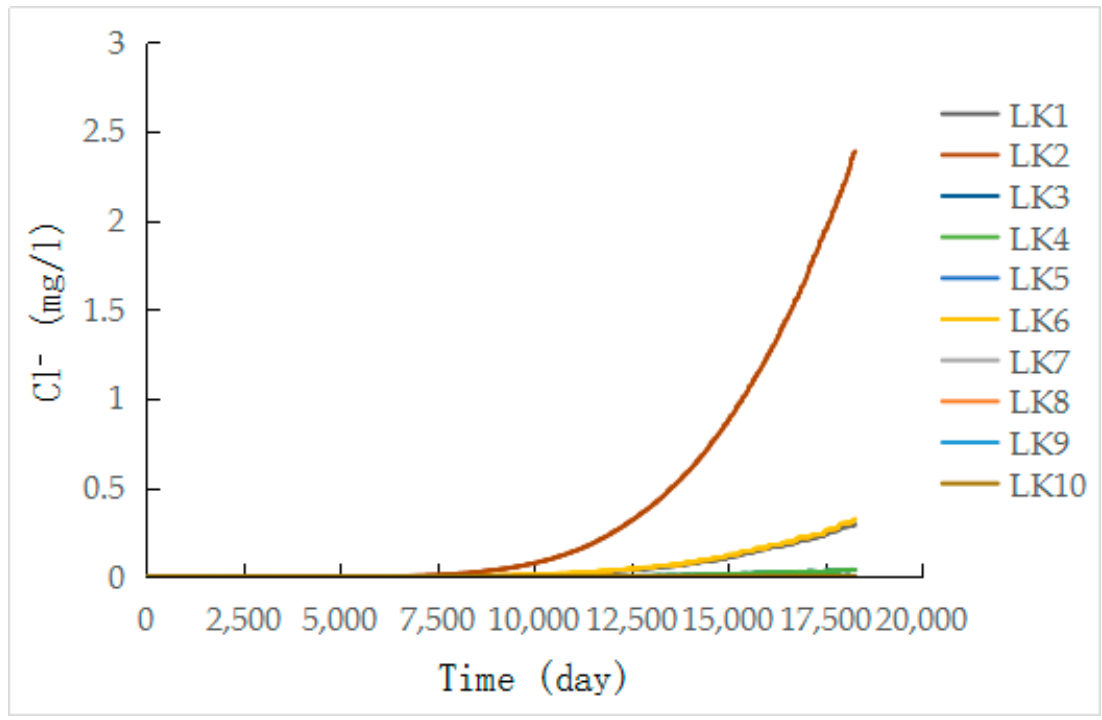

Figure 6. The concentration curve of $\mathrm{Cl}^{-}$.

Forecasts indicate that the solute will mainly migrate in a southeast direction, before gradually moving to the north in the main direction. After continuous discharge for 21 years, LK02 in the Liuzheng area will be the first well to be affected. With an increase in time, solutes will then gradually affect groundwater in some areas north of the Liuzheng water source. 


\subsection{Determination of Water Source Protection Areas}

\subsubsection{Empirical Formula Method}

The scope of the protection area of the Liuzheng water source is calculated using the empirical formula provided by the Technical guideline for delineating source water protection areas [44]:

$$
R=\alpha \times K \times J \times T / n
$$

where $R(\mathrm{~m})$ is the radius of the protection zone, $\alpha$ is the safety factor, it is generally $150 \%$; $K$ (m/day) is the aquifer permeability coefficient; $J$ is the hydraulic gradient; $T$ (day) is the horizontal migration time of the pollutant; and $n$ is effective porosity. According to the literature [44], when $T$ takes 100, $R$ is the radius of the primary protection area, and when $T$ takes $1000, R$ is the radius of the secondary protection area.

According to the identification and verification of groundwater flow simulation; the permeability coefficient of the aquifer in the Liuzheng area is about $250 \mathrm{~m} /$ day. The average hydraulic gradient in the Liuzheng area is about 0.00035 , the safety factor is $150 \%$, and the effective porosity is 0.15 . Using this information, results from Equation (5) show the radius of the primary protection zone to be $87.5 \mathrm{~m}$, and the radius of the secondary protection zone to be $875 \mathrm{~m}$.

\subsubsection{Numerical Simulation Method}

Using the MODPATH module for backtracking, 10 tracer particles were set for each production well to predict the capture range of tracer particles passing through 100 and 1000 days (Figure 7). The maximum migration distance of the tracer particles for 100 day is about $90 \mathrm{~m}$ (Figure 7a), and the maximum migration distance of 1000 day outside the fault is about $760 \mathrm{~m}$ (Figure $7 \mathrm{~b}$ ).

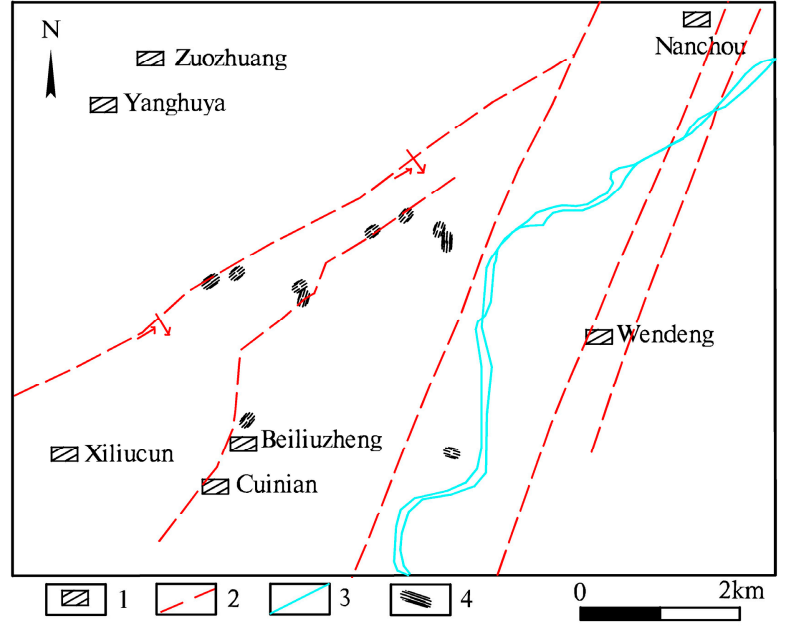

(a)

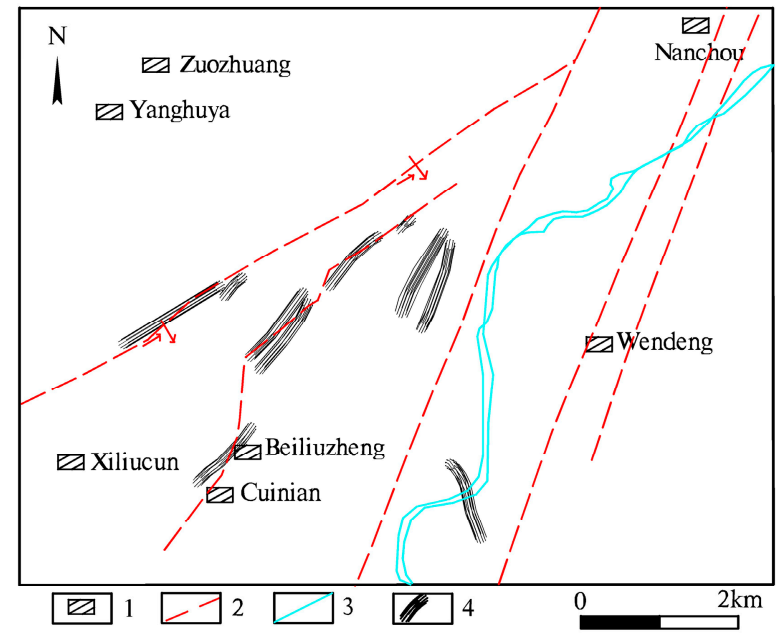

(b)

Figure 7. Tracing trajectory of tracer particles. (a) 100 day, (b) 1000 day; 1: Village; 2: Fault; 3: River; 4: Migration trajectory.

\subsubsection{Comparative Analysis}

For the division of the primary protection zone, the maximum migration distance obtained by the numerical simulation method is slightly larger than the radius calculated by the empirical formula method. For the division of the secondary protection zone, the maximum migration distance calculated by the numerical simulation method is slightly smaller than the radius calculated by the empirical formula method. The distance of the secondary protection zone calculated using the 
numerical simulation method is slightly smaller than the radius of the protection zone calculated using the empirical formula method. This finding is due to the calculation of the empirical formula method, where hydraulic gradient takes the average hydraulic gradient in the Liuzheng area. In the numerical simulation method, the hydraulic gradient near the mining location is greater than the hydraulic gradient away from the mining well location. The numerical method not only simulates the actual situation of the groundwater flow field, it also shows the anisotropy of karst development in the partition of permeability coefficient, water storage coefficient and dispersion. For example, when the permeability coefficient near the fault zone is large, the radius of the protection zone is therefore also slightly large. Our results indicate that the numerical method is relatively accurate recording the area of the primary protection area of the Liuzheng water source to be about $0.59 \mathrm{~km}^{2}$, and the area of the secondary protection area to be about $14.98 \mathrm{~km}^{2}$ (Figure 8).

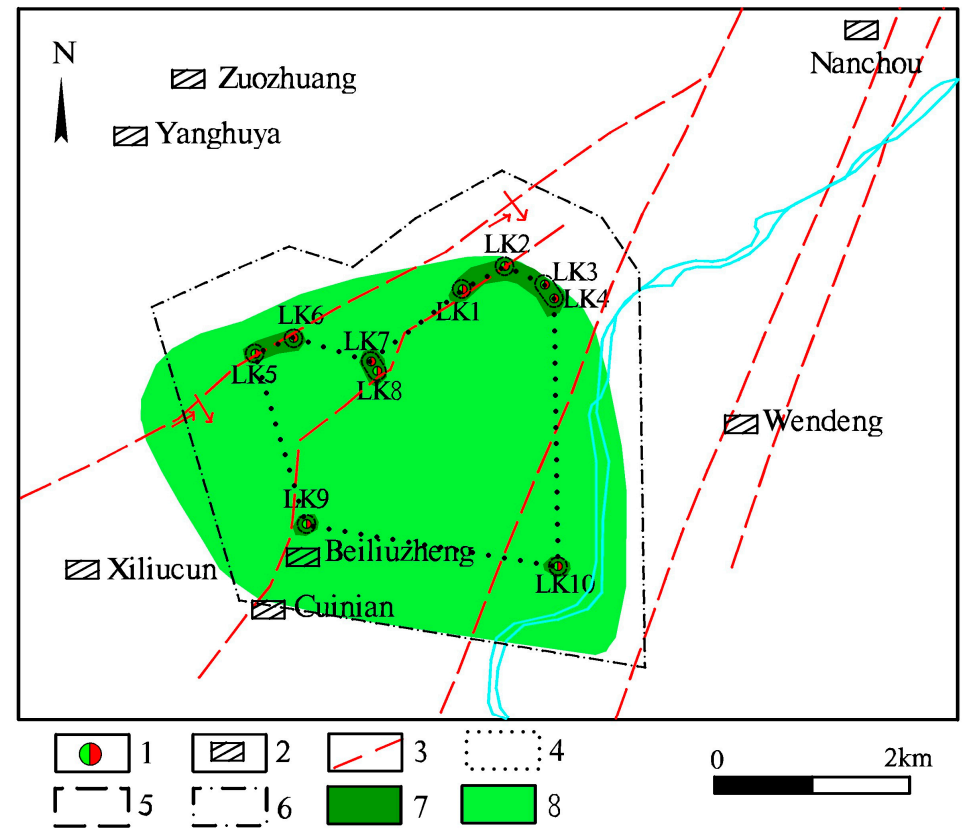

Figure 8. The scope of the protected area of the Liuzheng water source. 1: Mining wells; 2: Villages; 3: Faults; 4: Group well outsourcing line; 5: Primary protection area (experience formula method); 6: Secondary protection area (experience formula method); 7: Primary protection area (numerical simulation method); 8: Secondary protection area (numerical simulation method).

\section{Conclusions}

1. The tracer test results show that karst development in the Wangzhai and Hougao areas of Zibo are characterized by the coexistence of karst pores, karst fissures, fractures and pipelines, and that the degree of development is uneven. The runoff channel and the dispersion coefficient are anisotropic, and the overall dispersion coefficient is less than $15 \mathrm{~m}^{2} /$ day. In addition, the tracer concentration curve can be divided into three types: Single peak, double peak and triple peak. The Wangzhai experimental area is one of the recharge areas of the Dawu and Liuzheng water sources.

2. Using the numerical simulation optimization calculation, when extraction of the Liuzheng water source reaches $150,000 \mathrm{~m}^{3} /$ day, it will not only change the regional groundwater flow field in the Dawu karst water system, it will also make full use of groundwater resources. The solute transport model predicts that the proposed Wangzhai Chemical Industrial Park will have a certain potential pollution impact on the northern part of the Liuzheng water source area.

3. The empirical formula method and the numerical method can be used to divide the protected area of the Liuzheng water source, and to compare and analyze results of the protection area division 
of the two methods. Our results indicated that the numerical simulation method is suitable for use in this area. The area of the primary protection area is recorded as being $0.59 \mathrm{~km}^{2}$, and the area of the secondary protection area is $14.98 \mathrm{~km}^{2}$. Corresponding anti-pollution protection measures should therefore be implemented for all levels of the protected areas in accordance with relevant national regulations.

Author Contributions: Conceptualization, H.Z.; Investigation, X.L. and N.B.; Methodology, Y.D. and L.X.; Resources, L.Y. and Z.L.; Writing—original draft, H.Z. and Y.D.; Writing—review \& editing, L.X.

Funding: This article is supported by the National Natural Science Foundation of China (41772257) and the Doctoral Fund of Jinan University (XBS1817).

Acknowledgments: We acknowledge Guangyao Chi and Xinyu Hou of University of Jinan for their extensive input of ideas on this research. This project would not have been possible without the cooperation of the Shandong Institute of Geological Survey.

Conflicts of Interest: The authors declare no conflict of interest. The founding sponsors had no role in the design of the study; in the collection, analyses, or interpretation of data; in the writing of the manuscript, and in the decision to publish the results.

\section{References}

1. Hartmann, A.; Goldscheider, N.; Wagener, T.; Lange, J.; Weiler, M. Karst water resources in a changing world: Review of hydrological modeling approaches. Rev. Geophys. 2014, 52, 218-242. [CrossRef]

2. Yafeng, C.; Jiangtao, H.; Manli, W.; Yuekong, Z.; Fei, W. Exploration of risk assessment method towards groundwater contamination in karst region: A case study in Disu underground river system basin. Carsol. Sin. 2016, 35, 372-383.

3. Changli, L.; Xiuyan, W.; Dunyu, L.; Yuewen, Z. Risk assessment and control countermeasures of southern China's karst groundwater areal source pollution. Acta Geosci. Sin. 2017, 38, 910-918.

4. Butscher, C.; Huggenberger, P. Modeling the temporal variability of karst groundwater vulnerability, with implication for climate change. Environ. Sci. Technol. 2009, 43, 1665-1669. [CrossRef] [PubMed]

5. Hailin, Z.; Zhong, W.; Wei, P.; Yue, T.; Huan, Q. Using sulfur and oxygen isotope to trace the source of sulphate in Baotu spring area of Jinan. Geol. Surv. China 2019, 6, 75-80.

6. Liankai, Z.; Pengyu, L.; Xiaoqun, T.; Xiaojing, S.; Wen, L.; Zhenhua, Z.; Ting, Y.; Mingyu, S. Migration and Transformation of Dissolved Organic Matter in Karst Water Systems and an Analysis of Their Influencing Factors. Environ. Sci. 2018, 39, 2104-2116.

7. Jingyuan, H. Application of traditional hydrogeological investigation methods of groundwater environmental pollution survey in mining area. World Nonferrous Met. 2017, 15, 204-206.

8. Rudakov, D.V.; Rudakov, V.C. Analytical modeling of aquifer pollution caused by solid waste depositories. Ground Water 1999, 37, 352-357. [CrossRef]

9. Seyed, R.S.; Elias, R.; Shaharin, I.; Mohd, A.; Mohd, Z.; Sa'ari, M. Simulation of phosphorus movement in unconfined aquifer by means of Visual MODFLOW. J. Comput. Sci. 2010, 6, 446-449.

10. Lei, R.; Xingping, W.; Xun, L. Numerical simulation of groundwater pollutants transport in an industrial park of Chongqing based on Visual Modflow. J. Chongqing Normal Univ. Nat. Sci. 2018, 35, 72-78.

11. Xiaoer, Z. A Dissertation Submitted to Nanjing University for Degree of Doctor of Science. Ph.D. Thesis, Nanjing University, Nanjing, China, 2018.

12. Hamdan, I.; Wiegand, B.; Toll, M.; Sauter, M. Spring response to precipitation events using $\delta^{18} \mathrm{O}$ and $\delta^{2} \mathrm{H}$ in the Tanour catchment, NW Jordan. Isot. Environ. Health Stud. 2016, 52, 682-693. [CrossRef] [PubMed]

13. Morales, T.; de Valderrama, I.; Uriarte, J.; Antiguedad, I.; Olazar, M. Predicting travel times and transport characterization in karst conduits by analyzing tracer-breakthrough curves. J. Hydrol. 2007, 334, 183-198. [CrossRef]

14. Maloszewski, P.; Stichler, W.; Zuber, A.; Rank, D. Identifying the flow systems in a karstic-fissured-porous aquifer, the Schneealpe, Austria, by modelling of environmental ${ }^{18} \mathrm{O}$ and ${ }^{3} \mathrm{H}$ isotopes. J. Hydrol. 2002, 256, 48-59. [CrossRef]

15. McGuire, K.; McDonnell, J. A review and evaluation of catchment transit time modeling. J. Hydrol. 2006, 330, 543-563. [CrossRef] 
16. Schilling, K.E.; Wolter, C.F. A GIS-based groundwater travel time model to evaluate stream nitrate concentration reductions from land use change. Environ. Geol. 2007, 53, 433-443. [CrossRef]

17. Yang, Z. Shallow Groundwater Quality and Evaluation in Karst Areas of Urbanization. Master's Thesis, Guizhou University, Guiyang, China, 2009.

18. Yinghui, W.; Shihua, Q.; Jie, L.; Xinli, X.; Feifei, S.; Xiangqin, W.; Jun, W.; Huafeng, L.; Junpeng, Z. Distribution characteristics of organochlorinated pesticides in soils of karst caves in Guilin, Guangxi, China. Geol. Bull. China 2007, 26, 1470-1475.

19. Mei, Y. Controlling factor and migration characteristic research of organic pollutant in typical karst underground rivers: A case of Nanshan karst valley in Chongqing. Master's Thesis, Southwest University, Chongqing, China, 2010.

20. Jin, L. Present situation of groundwater pollution and its prevention and control measures. Energy Conserv. 2018, 6, 92-115.

21. Yang, L.; Yin, Y.; Cheng, G. Prediction of groundwater environment of a chemical plant based on Visual MODFLOW. J. Green Sci. Technol. 2017, 18, 88-93.

22. Aiping, Q.; Jimei, H. Investigation on the pollution status of organic matter in karst groundwater in Jinan. Liferatue Inf. Prevent. 2001, 7, 637-700.

23. Ekmekci, M. Pesticide and nutrient contamination in the kestel polje-kirkgoz karst springs, southern turkey. Environ. Geol. 2005, 49, 19-29. [CrossRef]

24. Markovic, T.; Miko, S.; Kapelj, S.; Buljan, R.; Larva, O.; Peh, Z. Behaviour of metals and nutrients in soils and groundwater of a karst polje. J. Geochem. Explor. 2006, 88, 124-129. [CrossRef]

25. Andreo, B.; Goldscheider, N.; Vadillo, I.; Vías, J.M.; Neukum, C.; Sinreich, M.; Jiménez, P.; Brechenmacher, J.; Carrasco, F.; Hötzl, H. Karst groundwater protection: First application of a pan-european approach to vulnerability, hazard and risk mapping in the sierra de líbar (southern spain). Sci. Total Environ. 2006, 357, 54-73. [CrossRef] [PubMed]

26. Chen, L.; Xing, C. Different physiognomy types in karst region, the groundwater pollution risk assessment-resistance in Qingzhen in Guizhou area as an example. J. Guiyang Univ. Nat. Sci. 2015, 10,55-60.

27. Hadžić, E.; Lazović, N.; Mulaomerović-Šeta, A. The importance of groundwater vulnerability maps in the protection of groundwater sources. Key study: Sarajevsko polje. Procedia Environ. Sci. 2015, 25, 104-111. [CrossRef]

28. Andreo, B.; Ravbar, N.; Vías, J.M. Source vulnerability mapping in carbonate (karst) aquifers by extension of the cop method: Application to pilot sites. Hydrogeol. J. 2009, 17, 749-758. [CrossRef]

29. Yuqun, X. Present situation and prospect of groundwater numerical simulation in China. Geol. J. China Univ. 2010, 16, 1-6.

30. Saravanan, R.; Balamurugan, R.; Karthikeyan, M.S.; Rajkumar, R.; Anuthaman, N.G.; Gopalakrishnan, A.N. Groundwater modeling and demarcation of groundwater protection zones for tirupur basin-a case study. J. Hydro-Environ. Res. 2011, 5, 197-212. [CrossRef]

31. Jang, C.S.; Chen, S.K. Integrating indicator-based geostatistical estimation and aquifer vulnerability of nitrate-n for establishing groundwater protection zones. J. Hydrol. 2015, 523, 441-451. [CrossRef]

32. Klaas, D.K.S.Y.; Imteaz, M.A.; Arulrajah, A. Development of groundwater vulnerability zones in a data-scarce eogenetic karst area using head-guided zonation and particle-tracking simulation methods. Water Res. 2017, 122, 17-26. [CrossRef]

33. Hao, C. Study on Delineating Groundwater Source Protection Zones in Sihe Alluvial Fan. Master's Thesis, China University of Geosciences, Beijing, China, 2018.

34. Guangchang, J.; Teng, M. Partitioning method of the groundwater wellhead protection Zone. Saf. Environ. Eng. 2016, 23, 36-39.

35. Bei, Z.; Jianjun, L. Simulation of groundwater polluted contamination migration based on Visual Modflow. J. Shihezi Univ. Nat. Sci. 2015, 33, 787-792.

36. Xueyu, Z.; Jianli, L.; Junjie, Z.; Yudao, C. Distribution and migration characteristics of petroleum pollutants in fractured karst water in Zibo, Shandong. Sci. China 2000, 30, 479-485.

37. Dapeng, G.; Fengxin, K.; Huanliang, C.; Jianmei, C.; Wei, L. Numerical simulation and optimal exploitation scheme for the karst groundwater recourses system of Fengshui spring basin in Zibo region, Shandong Province, China. Carsol. Sin. 2017, 36, 327-338. 
38. Shandong Institute of Geological Survey. Hydrogeological Exploration Report of LiuzhengWater Source; Shandong Institute of Geological Survey: Jinan, China, 2018.

39. Feng, X. Study of Groundwater Contamination Transport Simulation on a Project in Southwest Karst Area Based on Visual MODFLOW. Master's Thesis, Hefei University of Technology, Hefei, China, 2014.

40. Shandong Institute of Geological Survey. Prediction of the Impact of the New Site Planning of the Chemical Industry Enterprises in Zhangdian on the Groundwater Environment; Shandong Institute of Geological Survey: Jinan, China, 2011.

41. Hengxiang, Z.; Liting, X.; Hua, X.; Guangyao, C.; Xinyu, H. Application of tracer test in the study of preferential runoff path of Jinan spring group. Ground Water 2017, 39, 5-7.

42. Shuya, H.; Ming, N.; Quansheng, Z.; Siyuan, Y.; Xinmin, W.; Jianwei, Z. Hydrodynamic dispersion parameters of coastal wetlands in Panjin based on field dispersion test on groundwater. Wetland Sci. 2015, 13, 327-331.

43. Dexin, H. Determination of dispersion coefficient using a single observation well. Site Invest. Sci. Technol. 1995, 2, 13-16.

44. HJ338-2018. Technical Guideline for Delineating Source Water Protection Areas; China Environmental Science Press: Beijing, China, 2018.

(C) 2019 by the authors. Licensee MDPI, Basel, Switzerland. This article is an open access article distributed under the terms and conditions of the Creative Commons Attribution (CC BY) license (http://creativecommons.org/licenses/by/4.0/). 